\title{
PD-L2 modulates asthma severity by directly decreasing dendritic cell IL-12 production
}

\author{
IP Lewkowich ${ }^{1}$, S Lajoie ${ }^{2}$, SL Stoffers ${ }^{1}$, Y Suzuki $^{3}$, PK Richgels ${ }^{1}, K_{\text {Dienger }}{ }^{1}$, AA Sproles ${ }^{1}$, H Yagita $^{4}$, \\ Q Hamid ${ }^{5}$ and M Wills-Karp ${ }^{2}$
}

Studies examining the role of programmed death 1 (PD-1) ligand 2 (PD-L2)/PD-1 in asthma have yielded conflicting results. To clarify its role, we examined the PD-L2 expression in biopsies from human asthmatics and the lungs of aeroallergen-treated mice. PD-L2 expression in bronchial biopsies correlated with the severity of asthma. In mice, allergen exposure increased PD-L2 expression on pulmonary myeloid dendritic cells (DCs), and PD-L2 blockade diminished allergen-induced airway hyperresponsiveness (AHR). By contrast, PD-1 blockade had no impact, suggesting that PD-L2 promotes AHR in a PD-1-independent manner. Decreased AHR was associated with enhanced serum interleukin (IL)-12 p40, and in vitro stimulation of DCs with allergen and PD-L2-Fc reduced IL-12 p70 production, suggesting that PD-L2 inhibits allergen-driven IL-12 production. In our model, IL-12 did not diminish T helper type 2 responses but rather directly antagonized IL-13-inducible gene expression, highlighting a novel role for IL-12 in regulation of IL-13 signaling. Thus, allergen-driven enhancement of PD-L2 signaling through a PD-1-independent mechanism limits IL-12 secretion, exacerbating AHR.

\section{INTRODUCTION}

Allergic asthma is an inflammatory lung disease whose prevalence continues to rise in developed nations. Although the origins of allergic asthma are complex, excessive activation of T helper type 2 (Th2) cells specific for normally innocuous environmental allergens drives disease pathology. Thus, in asthmatic individuals, allergen exposure triggers the development of allergen-specific Th2 cells producing interleukin (IL)-4, IL-5, and IL-13, which induce immunoglobulin $\mathrm{E}$ (IgE), eosinophilia, mucus hypersecretion, and airway hyperresponsiveness (AHR). ${ }^{1}$ By contrast, non-asthmatic individuals develop protective responses mediated by $\mathrm{IL}-10$ and transforming growth factor- $\beta$ secreting regulatory $\mathrm{T}$ cells. ${ }^{2,3}$ Thus, the type of T-cell response induced following allergen exposure is an important determinant of susceptibility to allergen-induced AHR.

In vivo, dendritic cells (DCs) represent the most potent professional antigen-presenting cells in the lung, and they have been identified as key players in promoting both pathogenic or protective T-cell responses. ${ }^{4}$ In the lung, DCs lie immediately below the epithelial cell layer and extend their dendrites into the lumen, capture inhaled allergens, and then migrate to lungdraining lymph nodes where they present captured allergens to naive T cells. ${ }^{5,6}$ Many factors influence the ability of DCs to promote pathogenic vs. protective T-cell responses. Allergen presentation by myeloid DCs (mDCs) promotes both initiation of AHR in naive animals ${ }^{4,7}$ and exacerbations in previously sensitized animals, ${ }^{6}$ whereas allergen presentation by plasmacytoid DCs prevents the initiation of $\mathrm{AHR}^{8}$ and limits allergic inflammation in previously sensitized hosts. ${ }^{9}$ DCs also influence the development of allergen-induced AHR through production of T-cell skewing cytokines. We have recently demonstrated that the production of high levels of IL-23 by pulmonary mDCs is associated with the development of a mixed Th2/Th17 cytokine profile that ultimately results in the development of severe AHR. ${ }^{4,10}$ By contrast, the development of weak AHR observed in $\mathrm{C} 3 \mathrm{H} / \mathrm{HeJ}$ mice is associated with the production of IL-12, ${ }^{11}$ and administration of exogenous IL-12

\footnotetext{
${ }^{1}$ Division of Cellular and Molecular Immunology, Department of Pediatrics, Cincinnati Children's Hospital Medical Center, Cincinnati, Ohio, USA. ${ }^{2}$ Bloomberg School of Public Health, John Hopkins University, Baltimore, Maryland, USA. ${ }^{3}$ Division of Pulmonary Medicine, Department of Medicine, Keio University School of Medicine, Tokyo, Japan. ${ }^{4}$ Department of Immunology, Juntendo University School of Medicine, Tokyo, Japan and ${ }^{5}$ Meakins-Christie Laboratories, Faculty of Medicine, McGill University, Montreal, Quebec, Canada. Correspondence: IP Lewkowich (lan.Lewkowich@cchmc.org)
} 
limits the severity of AHR in asthma-susceptible A/J animals. ${ }^{12}$ Finally, the types of co-stimulatory molecules expressed by DCs also control T-cell development such that expression of CD80, CD86, and OX40L all promote allergic disease, ${ }^{13-15}$ while ICOS-L (inducible costimulatory ligand) expression induces the development of regulatory $\mathrm{T}$ cells and promotes inhalational tolerance. ${ }^{16}$ Thus, by virtue of the subsets of DCs involved in allergen presentation and the nature of the cytokines or co-stimulatory molecules produced, DCs regulate the development of pathogenic vs. protective T-cell responses.

Another way DCs regulate T-cell responses is through expression of programmed death 1 (PD-1) family members. The PD- 1 family consists of PD-1 ligand 1 (PD-L1; found on DCs, T cells, B cells, and structural cells), ${ }^{17,18}$ PD-L2 (expressed on DCs and macrophages) ${ }^{18}$ and PD-1 (expressed on T cells, DCs and macrophages). ${ }^{19-21}$ In general, stimulation of T cells through PD-1 or PD-L1 limits CD3-mediated activation of $\mathrm{T}$ cells. Indeed, PD-1 stimulation is responsible for the T-cell "exhaustion" observed in models of chronic viral infection (lymphocytic choriomeningitis virus, HIV), ${ }^{22,23}$ contributes to allograft tolerance, ${ }^{24}$ and prevents autoimmune disease. ${ }^{17,25}$ Interestingly, despite the generally inhibitory role for PD-1 in regulating T-cell activation, the role of the PD-1/PD-L axis in regulating allergic asthma is uncertain, with some reports suggesting a protective role for this pathway, ${ }^{9,26-29}$ and others reporting a pro-asthmatic role for either PD-L1 ${ }^{27}$ or PD-L2. ${ }^{30}$

Herein, we sought to clarify the role of PD-L2 in allergeninduced AHR. We demonstrate that in both mice and humans, increased PD-L2 expression is associated with more severe AHR. Supporting a role for a PD-L2 in modulating asthma severity, in vivo blockade of PD-L2 reduces the severity of allergen-driven AHR. Surprisingly, PD-L2 blockade does not alter the production of Th2 cytokines, the composition of inflammatory cells in the bronchoalveolar lavage (BAL), or synthesis of IgE, but rather, enhances the ability of DCs to secrete IL-12 p70, and simultaneous blockade of both PD-L2 and IL-12 abrogate the protective effects observed upon blockade of PD-L2 alone. Strikingly, blockade of PD-1 had no impact on AHR or systemic IL-12 levels, suggesting that PD-L2 regulates asthma severity in a PD-1-independent manner. Furthermore, in our model, increased IL-12 production is not associated with decreased Th2 cytokine production. However, we demonstrate that IL-12 directly antagonizes IL-13-driven gene induction and STAT6 (signal transducer and activator of transcription factor 6) phosphorylation, providing a mechanism whereby IL-12 may limit the severity of allergeninduced AHR. Collectively, these results demonstrate that PD-L2, through an unknown receptor, limits IL-12 secretion, thereby enhancing the magnitude of allergen-induced AHR.

\section{RESULTS}

mDC expression of PD-L2 is associated with ongoing AHR In this study, we sought to clarify the role of PD-L2 in asthma. To this end, we compared PD-L2 expression in the lung following sequences of allergen exposures designed to induce either robust AHR, or the development of tolerance. As such, we exposed mice to house-dust mite (HDM) extract intratracheally (IT) on days 0 and 14 , a protocol previously shown to induce robust AHR in A/J mice. ${ }^{4}$ As expected, HDM exposure induced robust AHR (Figure 1a) as measured by monitoring airway pressure changes over time, as described elsewhere. ${ }^{31}$ We then examined PD-L2 messenger-RNA expression in the lungs of mice at 2, 24, or $72 \mathrm{~h}$ after the last IT challenge. PD-L2 expression was upregulated by HDM at $2 \mathrm{~h}$ and peaked $24 \mathrm{~h}$ later (Figure 1b). To determine whether PD-L2 induction was unique to HDM, A/J mice were sensitized intraperitoneally (IP) with ovalbumin (OVA) in saline on day 0 and challenged IT with OVA on days 14 and 21. As previously reported, ${ }^{11}$ this treatment regimen induced AHR (Figure 1a). As with HDM, OVA exposure also induced a rapid increase in PD-L2 expression that peaked at $24 \mathrm{~h}$ (Figure 1b). Interestingly, despite an identical number of allergen exposures, mice receiving OVA exclusively IT, a regimen known to induce tolerance rather than $\mathrm{AHR}^{8,16}$ demonstrated no induction of AHR (Figure 1a) and failed to upregulate PD-L2 expression significantly, suggesting that enhanced PD-L2 expression is associated with allergen-induced AHR (Figure 1b).

PD-L2 is chiefly expressed by antigen-presenting cells; ${ }^{18}$ however, multiple pulmonary DC populations have been described to date. To determine whether PD-L2 was differentially expressed on different DC subsets, mice were treated IT with HDM on day 0 and fluorescent HDM (AF405-HDM) on day 14 to facilitate the identification of allergen-bearing DCs by flow cytometry. Seventy-two hours after HDM exposure, five distinct populations of $\mathrm{CD}_{11 \mathrm{c}^{+}}$cells could be identified by flow cytometry, including alveolar macrophages, plasmacytoid DCs, neutrophils, inflammatory DCs, and mDCs (see Supplementary Figure S1a online). Although alveolar macrophages demonstrated some allergen uptake, and alveolar macrophages, neutrophils, and inflammatory DCs all expressed some PD-L2 after allergen challenge, $\mathrm{mDCs}$ were the only population simultaneously positive for both AF405HDM and PD-L2 (see Supplementary Figure S1b online). Thus, $\mathrm{HDM}^{+} \mathrm{PD}-\mathrm{L} 2{ }^{+}$mDCs represented up to $\sim 15 \%$ of all mDCs found in the lung, while the increase in the frequency of other $\mathrm{HDM}^{+} \mathrm{PD}-\mathrm{L} 2{ }^{+} \mathrm{DC}$ populations was comparatively minor $(\leq 3 \%)$ (Figure 1c). Moreover, the levels of PD-L2 expression (as measured by mean fluorescence intensity) increased markedly on pulmonary $\mathrm{mDCs}$ after allergen exposures (Figure 1d). By contrast, the mean fluorescence intensity of PD-L2 expression was not significantly increased on other pulmonary DC populations (Figure 1d). These data suggest that pulmonary $\mathrm{mDCs}$ are the principal PD-L2expressing DC subset in the lung.

To determine whether a similar association between PD-L2 expression and increased asthma severity is present in human populations, we compared PD-L2 expression in bronchial biopsies from patients with mild asthma, severe asthma, and healthy control subjects. PD-L2 expression was undetectable in healthy control subjects (Figure 1e). In comparison to healthy controls, the expression of PD-L2 was enhanced in patients 

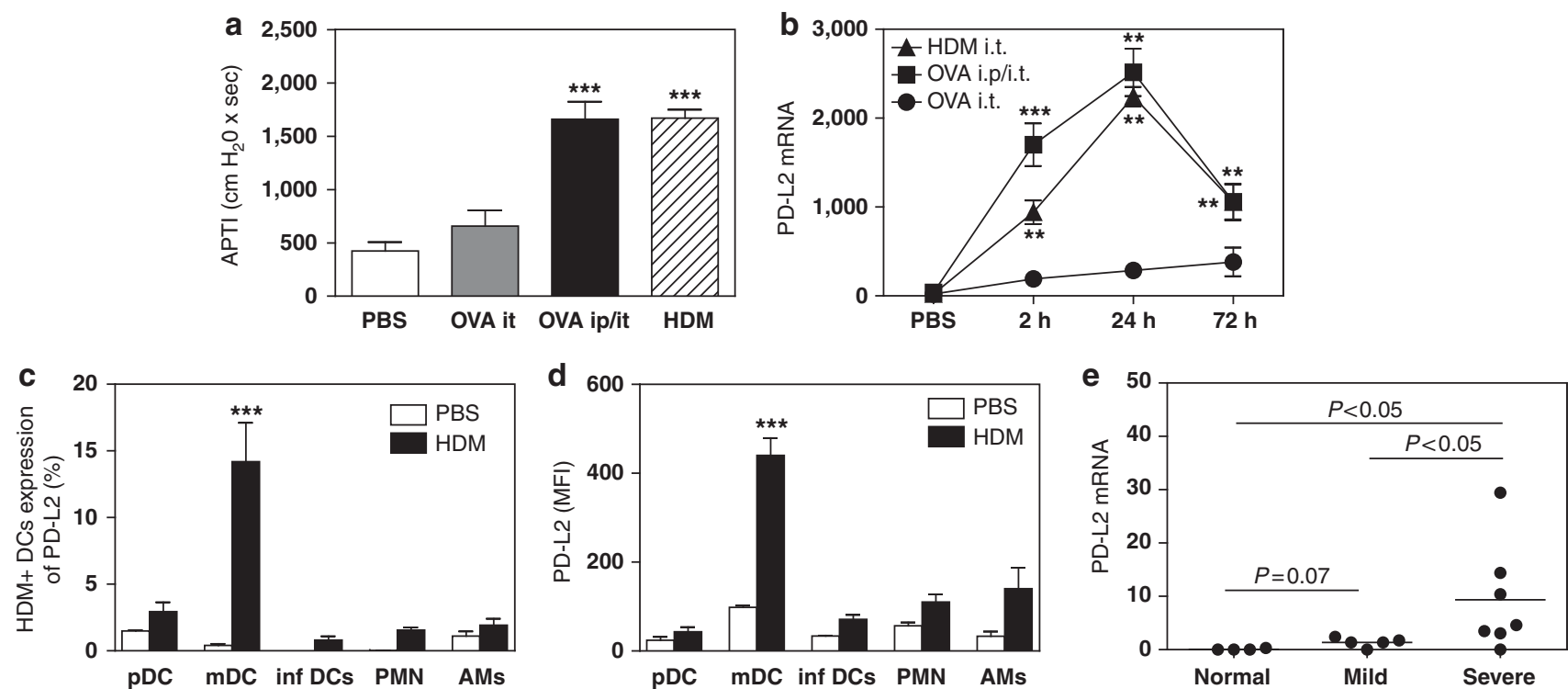

Figure 1 Programmed death-1 ligand 2 (PD-L2) expression is enhanced in the airways of asthmatic individuals and allergen-exposed mice. Mice were treated with phosphate-buffered saline (PBS-intratracheally (IT) on days 0 and 14), IT ovalbumin (OVA IT - 100 $\mu \mathrm{g}$ on days 0,14 , and 21 ), intraperitoneal (IP)/IT OVA (OVA IP/IT - $10 \mu \mathrm{g}$ OVA IP on day 0 followed by $100 \mu \mathrm{g}$ IT on days 14 and 21 ), or IT house-dust mite (HDM - $100 \mu \mathrm{g}$ on days 0 and 14). (a) Mice were killed $72 \mathrm{~h}$ after final allergen exposure to measure airway hyperresponsiveness via the airway pressure time index (APTI) method. (b) PD-L2 expression (normalized to mouse ribosomal protein S14) was measured by real-time PCR. $n=4$ mice per group. One representative experiment of two shown. Mean + s.e.m. are shown. ${ }^{* *} P<0.001$ and ${ }^{* *} P<0.01$ vs. PBS-treated mice. (c) The frequency of HDM + dendritic cells (DCs) of the indicated subsets expressing PD-L2 and (d) the mean fluorescent intensity (MFI) of PD-L2 expression on the total DC population (regardless of allergen uptake) was assessed by flow cytometry. $n=4$ mice per group. Mean + s.e.m. are shown. ${ }^{* \star *} P<0.001$ vs. PBS-treated mice. One representative experiment of two shown. (e) PD-L2 expression (normalized to human ribosomal protein S9) was assessed by PCR in samples taken from normal controls or individuals categorized as mild or severe asthmatics. Each point represents a single individual. AM, alveolar macrophages; inf, inflammatory; mdc, myeloid dendritic cell; pDC, plasmacytoid dendritic cell; PMN, polymorphonuclear leukocytes.

with severe asthma $(P<0.05$; Figure 1e). Moreover, while not significant, there was a trend towards increased PD-L2 expression in individuals with mild asthma $(P=0.07)$. Thus, PD-L2 expression is significantly elevated in individuals with severe disease.

\section{PD-L2 blockade limits the development of allergen-induced AHR}

To directly assess the role of PD-L2 in AHR in mice, we examined the effect of a PD-L2-blocking monoclonal antibody $\left(\mathrm{mAb}\right.$; clone TY25) ${ }^{32}$ on the development of allergen-induced AHR. As expected, HDM increased AHR, which was not impacted by an isotype control mAb (Figure 2a). By contrast, administration of anti-PD-L2 significantly reduced the development of HDM-induced AHR, demonstrating that PD-L2 modulates asthma severity (Figure 2a). Although PD-L2 is a ligand for PD- $1,{ }^{33}$ some reports suggest that PD-L2 can bind a receptor other than PD- $1 .{ }^{34,35}$ To determine whether PD-L2 enhances asthma through interactions with PD-1, we examined the impact of PD-1 blockade on the development of AHR. However, treatment with a mAb known to block interactions between PD-1 and both of its known ligands (PD-L1 and PD-L2; clone RMP1-14) ${ }^{36}$ had no impact on the magnitude of HDM-induced AHR in A/J animals (Figure 2b). This suggests that PD-L2 regulates the severity of AHR through a PD-1-independent mechanism.

As airway inflammation is a hallmark of allergen-induced asthma, we also examined the cells present in the BAL of mice
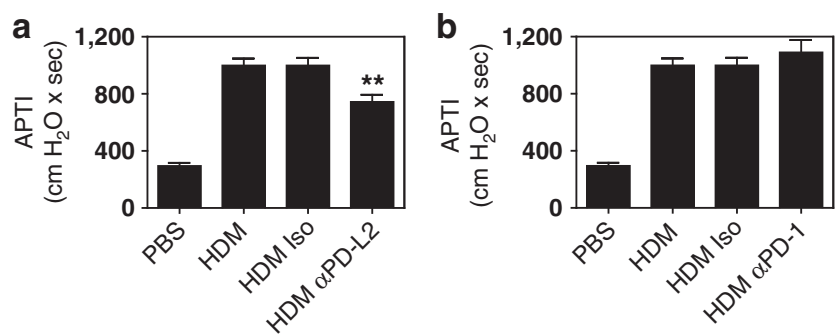

Figure 2 In vivo programmed death-1 ligand 2 (PD-L2) blockade, but not PD-1 blockade, limits the severity of allergen-induced airway hyperresponsiveness (AHR). (a) A/J mice were treated with phosphatebuffered saline (PBS) or house-dust mite (HDM) intratracheally on days 0 and $14,250 \mu \mathrm{g}$ of rat $\lg \mathrm{G}_{2 \mathrm{a}}$ (immunoglobulin $\mathrm{G}_{2 \mathrm{a}}$ ) control (Iso) or anti-PDL2 IP ( $\alpha$ PD-L2) on days $0,2,14$, and 16, and AHR was assessed via the airway pressure time index (APTI) method on day 17. (b) To determine $\mathrm{PD}-1$ dependence, $\mathrm{A} / \mathrm{J}$ mice were treated with $\mathrm{PBS}$ or HDM intratracheally on days 0 and 14 , and $250 \mu \mathrm{g}$ of rat IgG $\lg _{2 \mathrm{a}}$ control (Iso) or anti-PD-1 ( $\alpha \mathrm{PD}-1$ ) IP on days $0,2,14$, and 16 , and AHR was assessed via the APTI method on day 17. $n=30$ mice pooled from five independent experiments. Mean + s.e.m. are shown. ${ }^{\star \star} P<0.01$ vs. Iso. $P D-1$, programmed death-1.

following exposure to phosphate-buffered saline (PBS), HDM, $\mathrm{HDM}+$ isotype control mAb, or HDM + anti-PD-L2. We harvested BAL at the time of killing and performed differential cell counts. As expected, HDM exposure induced the recruitment of significant numbers of macrophages, eosinophils, neutrophils, and lymphocytes (Figure 3a). However, the BAL cell profile was unaffected by either the presence of control $\mathrm{mAb}$, anti-PD-L2 (Figure 3a) or anti-PD-1 (data not shown). 

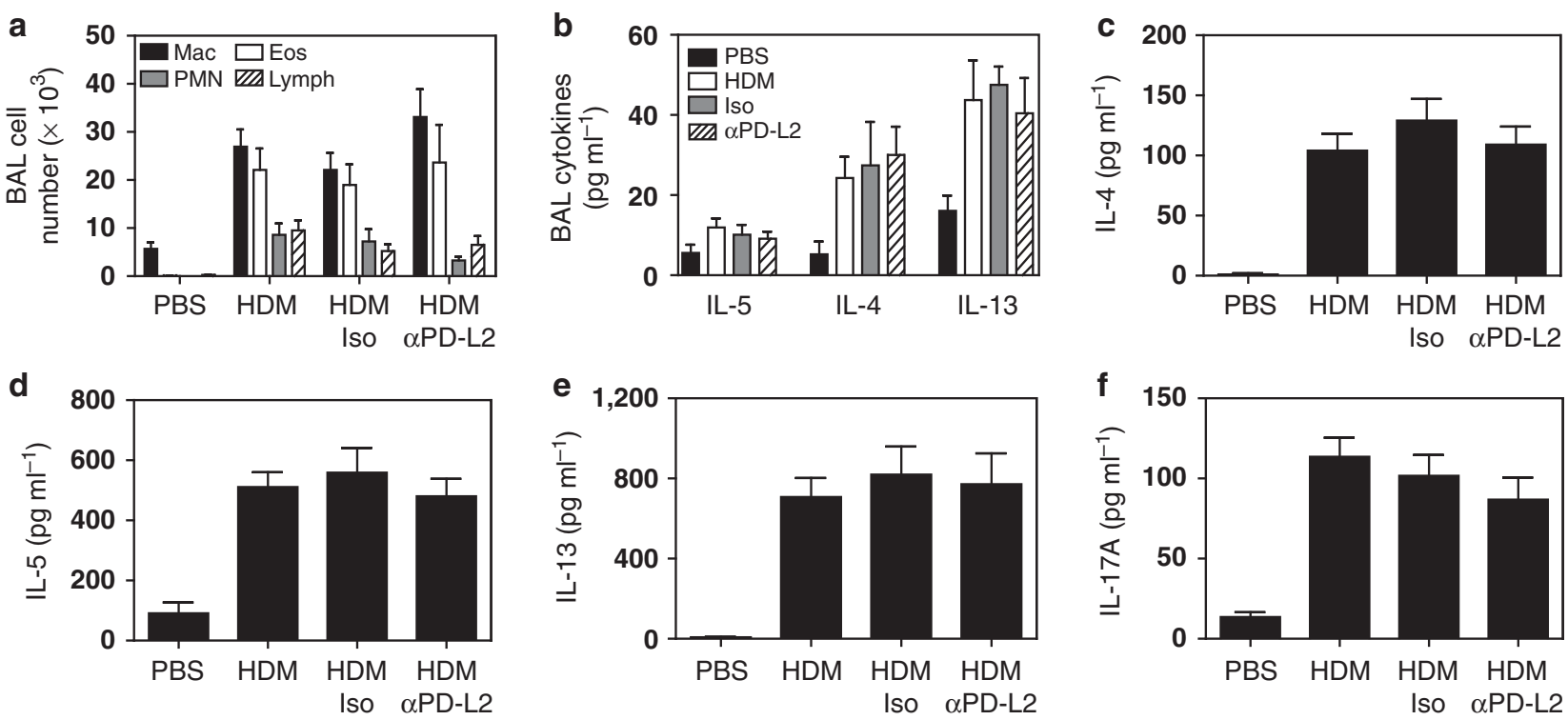

Figure 3 In vivo programmed death-1 ligand 2 (PD-L2) blockade does not alter T-cell cytokine production. A/J mice were treated with phosphatebuffered saline (PBS), house-dust mite (HDM), HDM + rat IgG I $_{2 a}$ (immunoglobulin $\mathrm{G}_{2 \mathrm{a}}$ ) control (Iso) or HDM + anti-PD-L2 ( $\alpha$ PD-L2) as described in Materials and Methods. (a) Cellular profile and (b) cytokine levels present in bronchoalveolar lavage (BAL) fluid taken at the time of killing. Lung cells were re-stimulated in vitro with HDM and the levels of (c) interleukin (IL)-4, (d) IL-5, (e) IL-13, and (f) IL-17A were assessed by enzyme-linked immunosorbent assay. $n=30$ mice from five independent experiments, or $n=10$ mice from two independent experiments for BAL cytokine assessment. Mean + s.e.m. are shown. Eos, eosinophils; Mac, macrophages; PMN, polymorphonuclear leukocytes.

Moreover, analysis of BAL cytokine levels demonstrated that although HDM increased the amounts of IL-4, IL-5, and IL-13 found in the BAL fluid, the levels of these cytokines were not significantly impacted by administration of isotype control or PD-L2-blocking mAbs (Figure 3b). To further characterize the immune response, we also examined HDM-stimulated cytokine production in lung cell cultures from mice treated in vivo with anti-PD-L2 or a control $\mathrm{mAb}$. As previously shown, HDM-treated A/J mice display a mixed Th2/Th17 cytokine profile, with robust production of IL-4, IL-5, IL-13, and IL-17A (Figure 3c-f) but no interferon (IFN)- $\gamma$ (data not shown). However, we observed no impact of in vivo anti-PD-L2 treatment on the production of any of the cytokines examined. Consistent with unaltered T-cell cytokine production or BAL cell recruitment, the activation status of pulmonary $\mathrm{mDCs}$ was also unaltered in mice treated with anti-PD-L2 (see Supplementary Figure S2 online). Thus, in our model, endogenous expression of $\mathrm{PD}-\mathrm{L} 2$ appears to regulate the severity of allergen-induced AHR, but not by amplifying the intensity of the underlying Th2 or Th17 responses.

\section{PD-L2 blockade significantly reduces airway mucus, whereas enhancing $\operatorname{lgG}_{2 a}$ production and systemic IL-12 p40 levels}

As mucus hypersecretion is also a hallmark of allergic asthma, we assessed mucus production in the lungs of mice treated with PD-L2-blocking Ab. As expected, compared with mice treated with PBS, those treated with HDM + isotype demonstrated markedly higher numbers of epithelial cells that stained with PAS (periodic acid-Schiff; Figure 4a). By contrast, treatment of HDM-exposed mice with anti-PD-L2 significantly decreased the number of PAS + epithelial cells (Figure 4a). To further characterize the immune response in HDM+anti-PD-L2treated A/J mice, we assessed serum Ig levels. HDM exposure induced increased total IgE (Figure $\mathbf{4 b}$; as a surrogate for allergen-specific IgE activity), ${ }^{37}$ HDM-specific $\operatorname{IgG}_{1}$ (Figure 4c), and $\mathrm{HDM}$ specific- $\operatorname{IgG}_{2 \mathrm{a}}$ (Figure 4d), but treatment with control $\mathrm{mAb}$ had no impact on serum Ig levels. Although PD-L2 blockade did not alter $\operatorname{IgE}$ or $\operatorname{IgG}_{1}$ production, it nearly doubled the levels of HDM-specific $\operatorname{IgG}_{2 \mathrm{a}}$. As $\operatorname{IgG}_{2 a}$ production is driven by Th1-associated cytokines, we examined the levels of IL-12 p40 in the serum (Figure 4e). IL-12 p40 levels in the serum were significantly enhanced in $\mathrm{HDM}+$ anti-PD-L2 treated mice, suggesting that PD-L2 can limit IL-12 p40 levels (Figure 4f). Interestingly, a similar increase was not observed in BAL, where IL-12 p40 levels were unaffected by anti-PD-L2 treatment (see Supplementary Figure $\mathbf{S 3}$ online). As increases in systemic IL-12 levels limit the development of allergeninduced AHR in A/J mice, ${ }^{12}$ the increase in serum IL-12 p40 may explain the decreased AHR observed in anti-PD-L2treated mice.

\section{IL-12 blockade abrogates the protective effect of anti-PD-L2 treatment}

To specifically test the hypothesis that increased IL-12 levels observed following PD-L2 blockade are responsible for decreased AHR, we treated mice with HDM in the presence of isotype control mAbs, $\mathrm{HDM}^{+}$anti-PD-L2, HDM + anti-IL12, or HDM + anti-PD-L2 ${ }^{+}$anti-IL-12. Although treatment of A/J mice with anti-IL-12 had no impact on AHR, treatment of mice with anti-PD-L2 significantly diminished AHR 

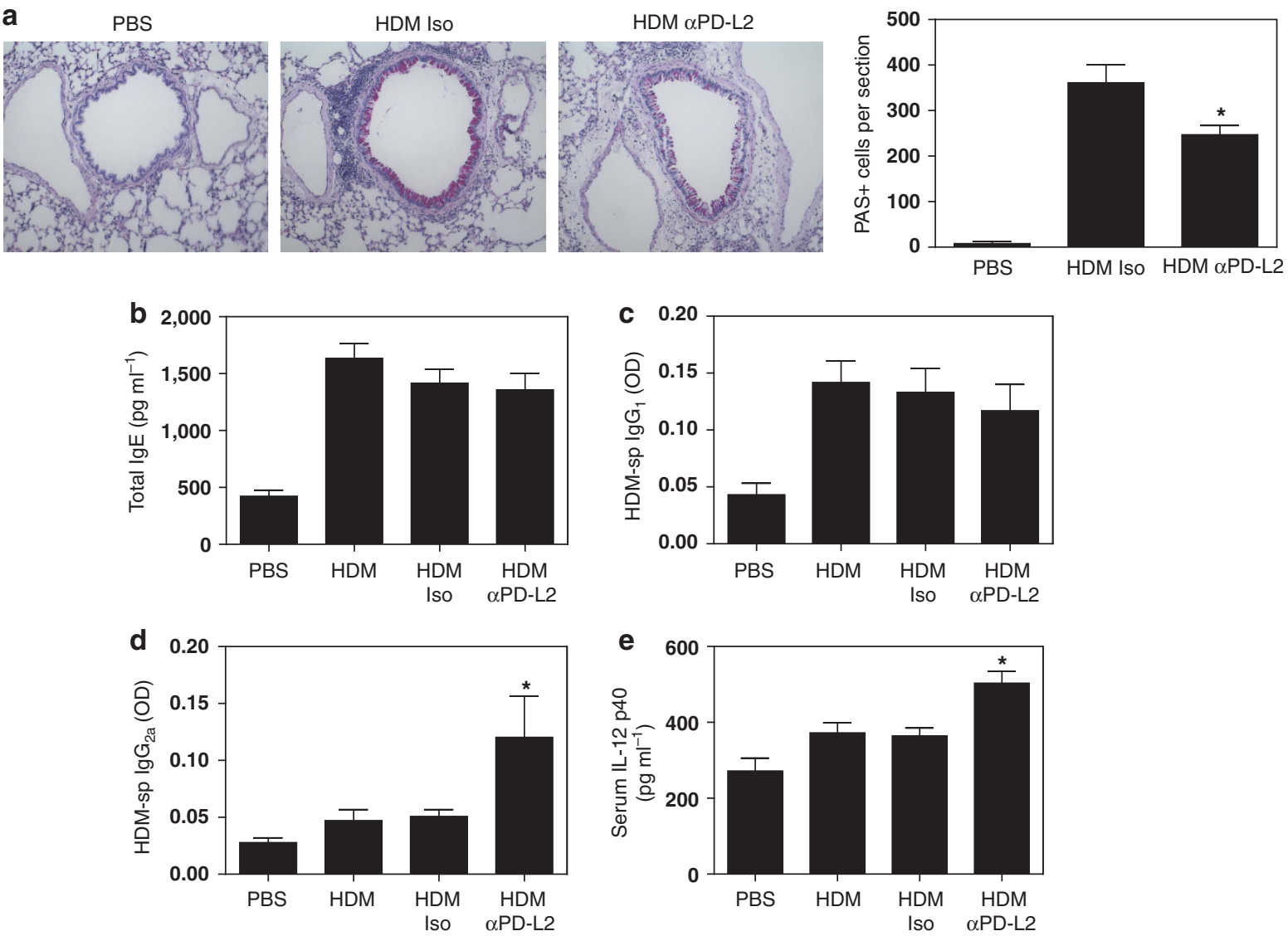

Figure 4 In vivo programmed death-1 ligand 2 (PD-L2) blockade enhances allergen-specific $\lg _{2 a}$ (immunoglobulin $\mathrm{G}_{2 \mathrm{a}}$ ) production and levels of systemic interleukin (IL)-12 p40. A/J mice were treated with phosphate-buffered saline (PBS), house-dust mite (HDM), $\mathrm{HDM}_{+}+$rat IgG $\mathrm{H}_{2 a}$ control (Iso) or HDM + anti-PD-L2 ( $\alpha$ PD-L2) as described in Materials and Methods. (a) Airway sections were stained with periodic acid-Schiff (PAS) to quantify mucussecreting cells, and the number of PAS + epithelial cells in four separate sections from four individual animals from each treatment group were determined. Serum collected at the time of harvest was assayed for levels of (b) total IgE, (c) HDM-specific (HDM-sp) IgG ${ }_{1}$, (d) $\mathrm{HDM}^{-s p} \lg \mathrm{H}_{2 a}$, and (e) IL-12 p40 by enzyme-linked immunosorbent assay. $n=30$ mice from five independent experiments. Mean + s.e.m. are shown. ${ }^{\star} P<0.05$ vs. Iso. OD, optical density.

(Figure 5a). However, treatment with anti-IL-12 abrogated the protective effect of PD-L2 blockade, as AHR in mice treated simultaneously with anti-PD-L2 and anti-IL-12 was indistinguishable from mice treated with isotype control $\mathrm{mAbs}$ alone (Figure 5a). Baseline AHR measurements (taken before injection of acetylcholine) demonstrated that although HDM increased basal AHR, this was not significantly different among the treatment groups (see Supplementary Figure S4 online).

Examination of HDM-restimulated cytokine production in lung cell cultures from anti-PD-L2, anti-IL-12, or anti-PD$\mathrm{L} 2+$ anti-IL-12-treated mice revealed that although HDM induced production of both Th2 (IL-4, IL-5, and IL-13; Figure 5b-d) and Th17 (IL-17A; Figure 5e) cytokines, there was no difference between the treatment groups. Similar results were observed when IL-5 and IL-13 expression levels were assessed by RT-PCR in samples taken from the lung immediately after sacrifice (see Supplementary Figure S5 online).

\section{PD-L2 stimulation inhibits allergen-induced IL-12 production}

As IL-12 p40 is a component of both bioactive IL-12 p70 and IL-23, which may have opposing effects on the development of allergen-induced $\mathrm{AHR},{ }^{4,11}$ we next determined whether changes in IL-12 p40 observed following PD-L2 blockade were due to specific effects on IL-12 p70 or IL-23. To this end, we cultured bone marrow-derived mDCs (BMDCs) with HDM on plates coated with PD-L2-Fc, PD-L1-Fc, or a control IgG-Fc. HDM induced IL-12 p70 production from BMDCs, and this production was unaltered by IgG-Fc (Figure 6a). DCs cultured on PD-L2-Fc-coated plates produced significantly less IL-12 p70 (Figure 6a), suggesting that stimulation with PD-L2-Fc can limit HDM-induced IL-12 p70 production. By contrast, stimulation of DCs with HDM in the presence of PD-L1$\mathrm{Fc}$, an alternative ligand for PD-1, did not impair IL-12 p70 production, suggesting that $\mathrm{PD}-1$ signaling is not regulating IL-12 production. The inhibition was specific for IL-12, as stimulation with PD-L2-Fc did not alter HDM-induced secretion of other DC-derived cytokines IL-23, IL-6, TNF $\alpha$ (Figure 6b-d), or IL-10 (data not shown). To directly test whether the capacity of PD-L2 signaling to limit bioactive IL-12 production was independent of PD-1, we cultured BMDCs on plates coated with either rIgG-Fc or PD-L2-Fc and stimulated these cells in the presence of anti-PD-1. As shown in Figure 6e, HDM-stimulated BMDCs plated on PD-L2-coated plates 

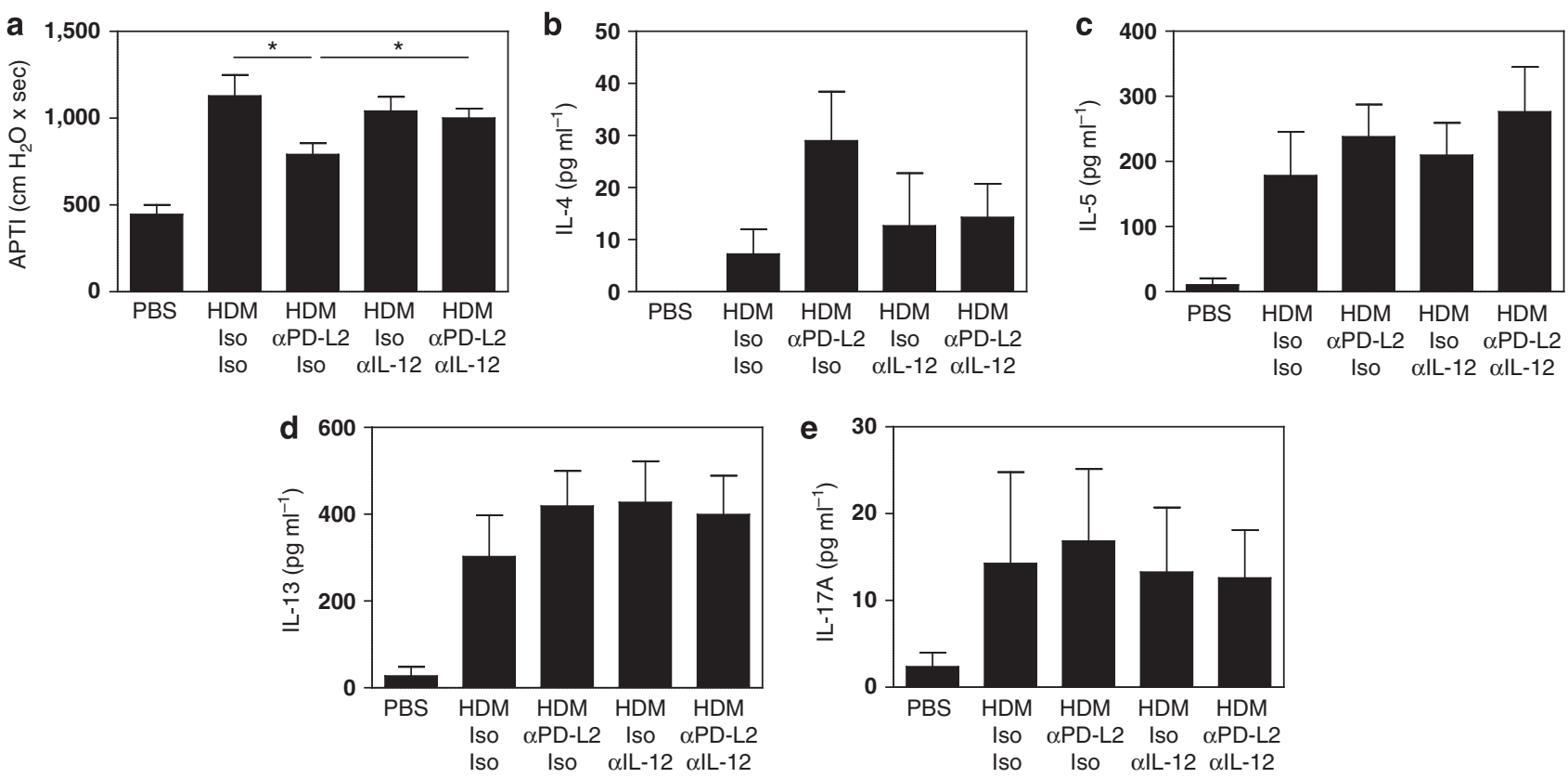

Figure 5 Simultaneous neutralization of endogenous interleukin (IL)-12 reverses decreased airway hyperresponsiveness (AHR) observed following programmed death-1 ligand 2 (PD-L2) blockade. A/J mice were treated with phosphate-buffered saline (PBS) or house-dust mite (HDM) intratracheally on days 0 and 14. Mice were given $250 \mu \mathrm{g}$ of rat $\lg _{2 a}$ (immunoglobulin $\mathrm{G}_{2 a}$ ) control (Iso) or anti-PD-L2 ( $\alpha P D-L 2$ ) IP on days $0,2,14$, and 16 and/or $1 \mathrm{mg}$ of rat IgG2a control (Iso) or anti-IL-12 ( $\alpha$ IL-12) IP on days -2 and 12. Mice were sacrificed on day 17 for assessment of AHR by the airway pressure time index (APTI) method (a). Lung cells were re-stimulated in vitro with HDM and levels of (b) IL-4, (c) IL-5, (d) IL-13, and (e) IL-17A were assessed by enzyme-linked immunosorbent assay. $n=10$ mice from two independent experiments. Mean + s.e.m. are shown. ${ }^{*} P<0.05$ compared with anti-PD-L2/ Iso-treated mice.
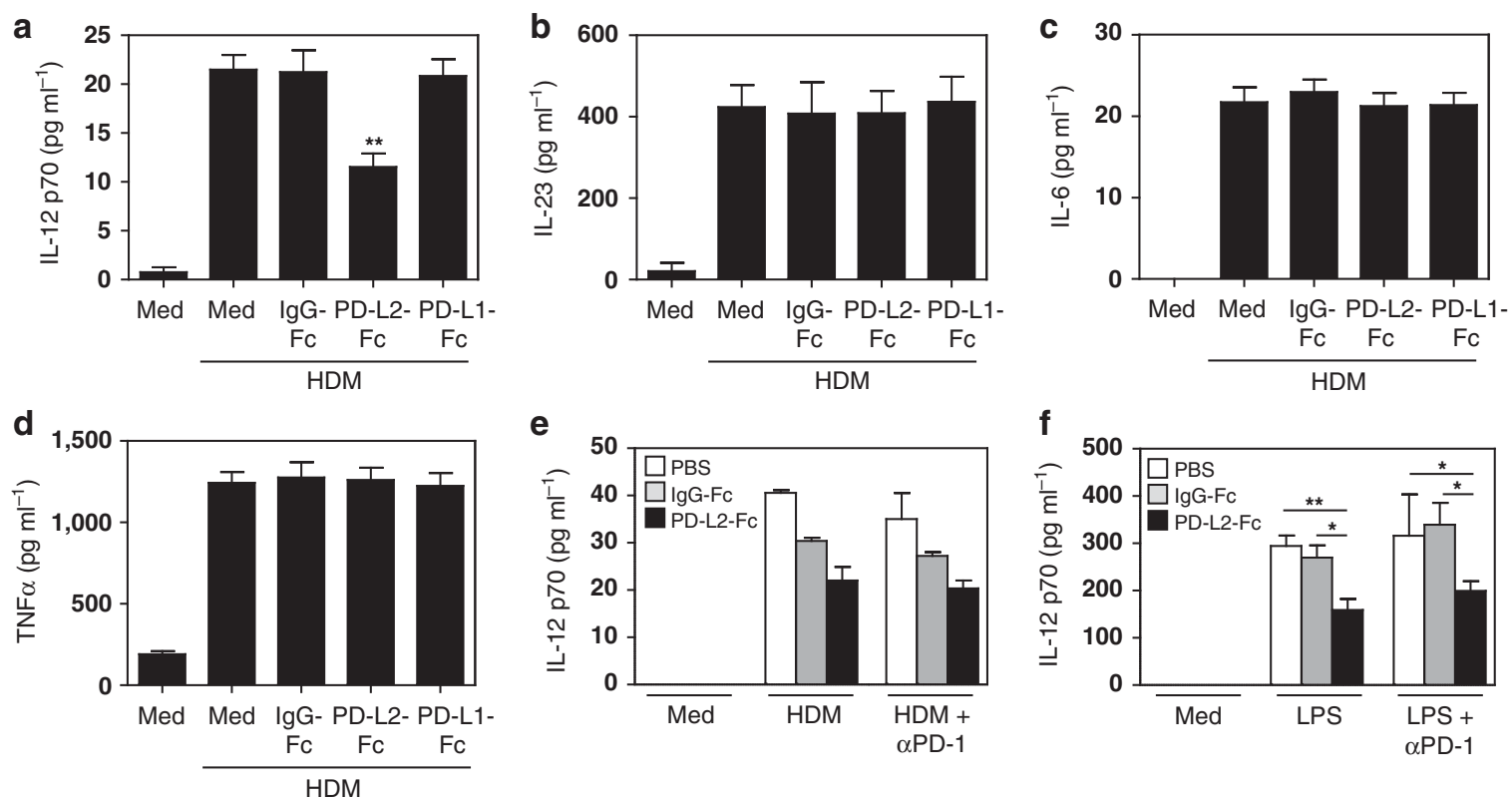

Figure 6 Stimulation of bone marrow-derived myeloid dendritic cells (BMDCs) with programmed death-1 ligand 2 (PD-L2)-Fc limits house-dust mite (HDM)-induced interleukin (IL)-12 p70, but not IL-23, IL-6, or tumor-necrosis factor $\alpha$ (TNF $\alpha$ ) production. BMDCs were grown as described in Materials and Methods. Cells were cultured in the presence of medium alone (Med) or HDM on plates coated with immunoglobulin G (IgG)-Fc, PD-L2-Fc, or PD-L1Fc. After $18 \mathrm{~h}$, supernatants were harvested, and the levels of (a) IL-12 p70, (b) IL-23, (c) IL-6, and (d) TNF $\alpha$ were determined by enzyme-linked immunosorbent assay (ELISA). $n=17$ individual wells, over three independent experiments. Mean + s.e.m. are shown. ${ }^{* *} P<0.01$ vs. HDM + IgG-Fcstimulated wells. BMDCs were cultured on plates coated with phosphate-buffered saline (open bars), IgG-Fc (gray bars), or PD-L2-Fc (black bars) in the presence of (e) HDM or (f) lipopolysaccharide (LPS) in the presence or absence of anti-PD-1. After $18 \mathrm{~h}$, supernatants were harvested and the levels of IL-12 p70 were determined by ELISA. $n=4$ wells from one of two experiments were performed. Mean + s.e.m. are shown. ${ }^{*} P<0.05$ and ${ }^{\star *} P<0.01$. 
produced less IL-12 p70, and their overall production of IL-12 p70 was not affected by the presence of PD-1-blocking $\mathrm{mAb}$. Similar results were observed when cells were stimulated with lipopolysaccharide (LPS; Figure 6f). Thus, stimulation with PD-L2 appears to specifically limit the capacity of DCs to secrete IL-12 p70 through a PD-1independent mechanism.

IL-12 directly antagonizes IL-13-induced gene expression Our observation that enhanced IL-12 production was associated with diminished AHR and mucus secretion, but unaltered production of IL-4, IL-5, IL-13, and IL-17A suggests that IL-12 may be regulating the severity of AHR by directly antagonizing signaling initiated by Th 2 cytokines. As IL- 13 has a major role in both allergen-induced AHR and mucus secretion, ${ }^{38}$ we tested the hypothesis that IL-12 was antagonizing IL-13 signaling. To this end, BMDCs were cultured with medium, IL-12, IL-13, or IL-12 + IL-13, and phosphorylation of STAT6, a signaling intermediate directly activated as a result of IL-13R engagement, was measured by western blot. As shown in Figure 7a, no detectable STAT6 phosphorylation was observed in medium or IL-12-stimulated BMDC cultures, whereas IL-13 induced robust STAT6 phosphorylation. In the presence of IL-12, IL-13-induced STAT6 phosphorylation was reduced but not completely abrogated (Figure 7a). To confirm that the reduced STAT6 phosphorylation observed in IL-12+IL-13-stimulated BMDC cultures was biologically significant, we subsequently examined the impact of IL-12 exposure on the expression of IL-13-driven genes by real-time (RT)-PCR. Although IL-13 induced the expression of FIZZ1, Arg1, and CD206 in BMDCs (Figure 7b) the induction of these genes was reduced following co-culture with IL-12 (Figure 7b). As reported elsewhere, ${ }^{28} \mathrm{IL}-13$ also induced the expression of PD-L2 on BMDCs. Interestingly, IL-13-driven PD-L2 expression was similarly inhibited in the presence of IL-12, suggesting that IL-12 may support its own production by antagonizing IL-13-driven PD-L2 expression. Not all IL-13driven genes were inhibited to the same extent, as IL-12 completely abrogated CD206 expression, whereas effects on other IL-13-driven genes (Arg1, Fizz1, PD-L2) were only partially abrogated, consistent with reduced, but not abrogated, phosphorylation of STAT6 observed in Figure 6a. By contrast, although IL-12 increased IFN- $\gamma$ expression in A/J BMDCs, this was not antagonized by IL-13, suggesting that IL-13 may not antagonize IL-12 signaling (see Supplementary Figure S6a online). Moreover, other Th1 cytokines can have a similar impact, as co-culture of BMDCs with IFN- $\gamma$ and IL-13 also abrogated IL-13-driven gene expression (see Supplementary Figure S6b online). In contrast to the inability of IL-13 to inhibit IL-12-driven genes, IL-13 strongly inhibited the induction of an IFN- $\gamma$-driven gene (PD-L1; see Supplementary Figure S6b online).

As IL-12 is widely known as an inducer of IFN- $\gamma$, we also determined whether the inhibition of IL-13 signaling by IL-12 was mediated by IFN- $\gamma$, through the blockade of IFN- $\gamma$ in cultures of BMDCs treated with IL-12 and IL-13. Inhibition of
IL-13-induced Fizz1 expression by IL-12 was completely reversed by addition of anti-IFN- $\gamma$ (see Supplementary Figure S6c online). However, it is unlikely that the effects of IL-12 on IL-13 signaling were entirely dependent upon induction of IFN- $\gamma$, as IL-12-mediated inhibition of STAT6 phosphorylation was observed as little as $15 \mathrm{~min}$ after IL-13 stimulation (too rapid to be due to de novo IFN- $\gamma$ synthesis) (Figure 7a), and IFN- $\gamma$ blockade did not restore the expression of Arg1 or CD206 to levels seen in the absence of IL-12 (see Supplementary Figure S6c online).

As epithelial cell responsiveness to IL-13 is sufficient to observe IL-13-induced alterations in AHR, mucous cell hyperplasia, and cell recruitment, ${ }^{39}$ it is also important to assess the ability of IL-12 to inhibit IL-13 signaling in airway structural cells. To this end, primary, murine tracheal epithelial cells were stimulated with IL-12, IL-13, or IL-12 + IL-13, and expression of IL-13-driven genes was assessed by RT-PCR. As shown in Figure 7c, IL-13 induced upregulation of IL-33, FIZZ1, AMCase, and SPRR2b. Consistent with the effects observed on BMDCs, IL-12 abrogated IL-13-driven induction of these genes in epithelial cells as well. Thus, IL-12 appears to directly inhibit IL-13-induced gene expression in both hematopoietic and structural cells through both IFN- $\gamma$ dependent and -independent mechanisms. Collectively these data demonstrate that IL-12 may limit AHR by directly antagonizing signaling of Th2-associated cytokines.

\section{DISCUSSION}

In this study, we have examined the role of the co-stimulatory molecule, PD-L2, in the development of allergen-induced AHR. We find that PD-L2 is upregulated in the lungs of individuals with severe (but not mild) asthma and in allergenexposed mice. In contrast to current dogma, which would suggest an inhibitory role for PD-L2 based on interactions with $\mathrm{PD}-1$, in vivo PD-L2 blockade reduces allergen-induced AHR. Although PD-L2 blockade reduced AHR, no significant impact on eosinophilia, IgE synthesis, or pulmonary DC activation was observed, suggesting that PD-L2 regulates AHR without impacting other features of allergic asthma. Collectively, these data suggest that PD-L2 expression regulates the overall magnitude of AHR in allergic asthma.

Our observation that PD-L2 signaling exacerbates asthma severity is in agreement with the previous report that PD-L2-Fc treatment enhances pulmonary inflammation in OVA (alum)sensitized BALB/c mice. ${ }^{30}$ However, in contrast to our results, it has also been reported that blockade of PD-L2 (but not PD-1) in OVA (alum)-sensitized BALB/c mice triggers increased AHR, a phenotype that was blocked with co-administration of IFN- $\gamma$ blocking antibodies. ${ }^{26}$ Similarly, AHR induced by exposure of $\mathrm{BALB} / \mathrm{c}$ mice to OVA (alum) or $\alpha \mathrm{GalCer}$ was increased in PD-L2-deficient mice due to increased IL-4 production by inducible natural killer T cells. ${ }^{27}$ Although these reports appear to conflict with our own, both are consistent with an increase in IL-12 production in the absence of PD-L2 signaling. In the study by Matsumoto et al, although IL-12 levels were not assessed, it is likely that the IFN- $\gamma$-driven increased AHR 

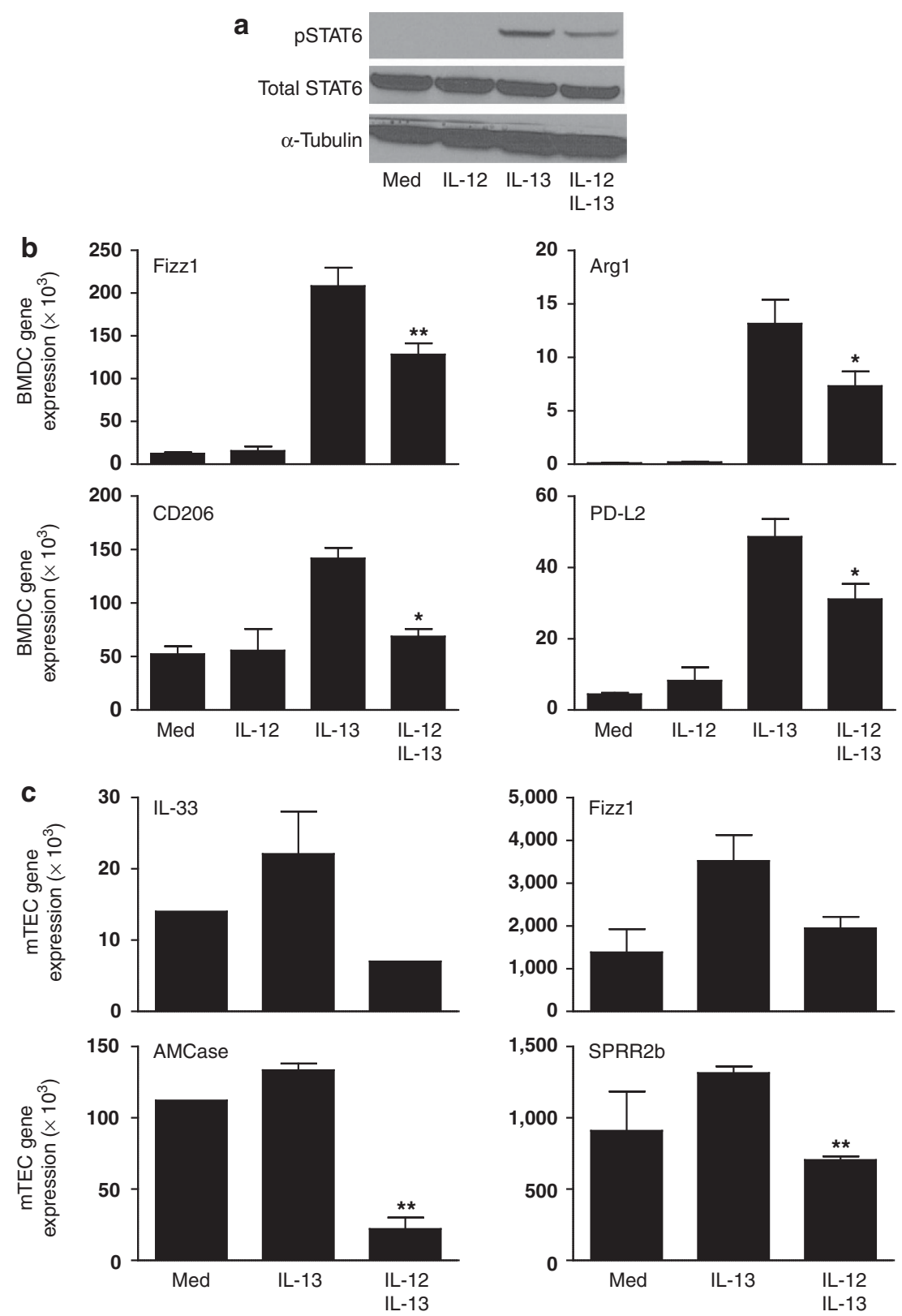

Figure 7 Interleukin (IL)-12 directly antagonizes IL-13-induced STAT6 (signal transducer and activator of transcription factor 6) phosphorylation and gene expression. Bone marrow-derived myeloid dendritic cells (BMDCs) were stimulated with medium alone (Med), IL-12 (10 ng ml ${ }^{-1}$ ), IL-13 $\left(10 \mathrm{ng} \mathrm{ml}^{-1}\right)$, or a combination of IL-12 + IL-13 for $15 \mathrm{~min}$. Proteins were separated on an sodium dodecyl sulfate gel and transferred to a PVDF membrane for detection of (a) pSTAT6, total STAT6, and as a loading control, $\alpha$-tubulin. BMDCs were stimulated with medium alone, IL-12 (10 ng ml ${ }^{-1}$ ), $\mathrm{IL}-13\left(10 \mathrm{ng} \mathrm{ml}^{-1}\right)$, or a combination of IL-12 + IL-13 for $18 \mathrm{~h}$. Messenger-RNA was harvested from the cell, and the expression of IL-13-driven genes was examined by real-time (RT-PCR). (b) Primary murine tracheal epithelial cells (mTECs) from C57BI/6 mice were treated with medium alone, IL-13 $\left(10 \mathrm{ng} \mathrm{ml}^{-1}\right)$, or IL-12 + IL-13 (both at $10 \mathrm{ng} \mathrm{ml}^{-1}$ ) for $24 \mathrm{~h}$. RNA was isolated, and (c) the expression of IL-13-driven genes was examined by RT-PCR. Mean + s.e.m. are shown. ${ }^{*} P<0.05$ and ${ }^{* *} P<0.01$ vs. IL-13-treated cultures. $n=4$ replicates for each condition tested. PD-L2, programmed death-1 ligand 2.

following PD-L2 blockade was driven by enhanced IL-12 production triggered by the lack of PD-L2 signaling. Moreover, IL-12 has been shown to drive IL-4 production in inducible natural killer T cells. ${ }^{40,41}$ Thus, as PD-L2 - / - mice lack a negative regulator of IL-12 production, inducible natural killer $\mathrm{T}$ cells from these mice display increased production of IL- $4 .^{27}$ Thus, collectively these studies support an important role for PD-L2 in the direct regulation of IL-12 synthesis.
Although IL-12 is classically regarded as a shaper of adaptive immunity, we find that the enhancement of IL-12 production observed following PD-L2 blockade does not regulate the balance of Th1- and Th2-associated cytokines in our model. It should be noted that although we observe robust PD-L2 expression after allergen challenge, we observe very few PD-L2 ${ }^{+}$mDCs immediately after a single allergen inhalation (data not shown). This suggests that the elevated IL-12 
observed following anti-PD-L2 treatment is likely only present during the effector phase, after allergen challenge. Thus, by inhibiting IL-12 levels exclusively during the effector phase, we find that PD-L2 directly promotes IL-13-driven sequelae (AHR, mucus hypersecretion) in allergic asthma independently of its effects on T-cell differentiation. Although it is conceivable that blockade of PD-L2 induces other changes which may contribute to the reduced AHR observed, simultaneous blockade of PD-L2 and IL-12 abrogates the protective effects of PD-L2 blockade, suggesting that the increased IL-12 observed is the dominant influence on the reduced AHR observed following PD-L2 blockade.

Although the precise gene products induced by IL-13 that promote the development of AHR are not clear, we have demonstrated that IL-12 can inhibit a number of IL-13-induced products with described roles in allergic asthma. In BMDCs, IL12 inhibits IL-13-induced expression of Fizz1 and Arg1, products associated with alternatively activated macrophages, which have been shown to have a pathogenic role in allergic asthma. ${ }^{42,43}$ Additionally, IL-12 also antagonized the IL-13induced expression of CD206 (a receptor shown to promote the phagocytosis of Derp1 ${ }^{44}$ in BMDCs. Although we do not observe an increase in overall HDM uptake by pulmonary DCs following blockade of PD-L2 in vivo, it is possible that PD-L2 blockade may subtly regulate the ability of DCs to take up or present specific allergenic peptides. In primary murine tracheal epithelial cells, IL-12 also inhibited the IL-13-induced expression of the genes encoding IL-33, (a Th2-inducing cytokine), ${ }^{45,46}$ AMCase (capable of enhancing allergen-driven IL13 production), ${ }^{47,48}$ and Fizzl (capable of inducing airway eosinophilia and airway remodeling ${ }^{49}$ ). We also see reduced IL-13-driven expression of Sprr2b following IL-12 treatment. Although little is known about the role of Sprr2b in the development of allergic asthma, it is induced by IL-13 but not IL-4. ${ }^{50}$ This is of particular interest as IL-13 is considerably more important than IL-4 in the induction of $\mathrm{AHR}^{38}$ suggesting that gene products induced by IL-13, but not IL-4, may have an important role in promoting AHR. Finally, we also demonstrate that IL-12 can directly antagonize STAT6 phosphorylation triggered by IL-13. It is likely that this effect may directly contribute to the reduced AHR observed in mice treated with anti-PD-L2 as STAT6 activation is critically required to trigger IL-13-induced AHR. ${ }^{39,51,52}$ Thus, despite unaltered levels of overall IL-13 production, IL-12 may impact the overall bioactivity of IL-13 through a number of different mechanisms.

That IL-12 may directly antagonize IL-13 signaling is also consistent with our previous observation that IL-12 blockade in A/J mice enhanced basal acetylcholine-induced airway constriction, suggesting that IL-12 can regulate airway tone in the absence of airway inflammation, ${ }^{11}$ and with reports showing IL-12-deficient mice can display enhanced AHR, with minimal impact on Th2 cytokine production. ${ }^{11,53,54}$ We also find elevated PD-L2 expression in individuals with severe asthma but not those suffering from milder forms of disease, suggesting that PD-L2 expression may also be correlated with asthma severity in humans as well. Although we did not examine IL-12 levels in individuals with severe vs. mild asthma, Morahan et al. ${ }^{55}$ have shown that a combination of single nucleotide polymorphisms in the human IL-12 p40 promoter, resulting in reduced LPS-stimulated IL-12 p40 secretion by peripheral blood mononuclear cells, is associated with more severe asthma, regardless of the atopic status of the individual. This suggests that impaired IL-12 production in humans also correlates with asthma severity but not T-cell skewing leading to initial sensitization (i.e., atopic status). Thus, our study highlights a previously underappreciated role of IL-12 in directly limiting asthma severity.

PD-L2 is typically thought to signal through PD-1 providing an inhibitory signal, limiting proliferation, and cytokine production of both $\mathrm{T}$ cells $\mathrm{s}^{30,56-58}$ and antigen-presenting cells. $^{20,21,59}$ However, interactions between PD-L2 and a receptor other than PD-1 were observed in a number of in vitro studies where it was demonstrated that such interactions enhance T-cell activity. ${ }^{33-35,60}$ Multiple lines of evidence suggest that, in our model, the dominant signals provided by $\mathrm{PD}-\mathrm{L} 2$ are mediated by a non-PD-1 receptor including: (1) in vivo blockade of PD-L2 and PD-1 have differential impacts on HDM-induced AHR, (2) stimulation with PD-L2, but not PD-L1, limits HDM- and LPS-induced IL12 production in vitro, and (3) the ability of PD-L2 to inhibit HDM or LPS-driven IL-12 p70 production in BMDCs is not abrogated in the presence of antibodies known to block the interactions between PD-L2 and PD-1. As stimulation of DCs with PD-L2, but not PD-L1, limits HDM-induced IL-12 production, we speculate that DCs also express the unidentified PD-L2 receptor and that signaling through this receptor in DCs directly regulates IL-12 $\mathrm{p} 70$ production. Intriguingly, as PD-L2 is primarily expressed by $\mathrm{mDCs}$, the ability of $\mathrm{PD}-\mathrm{L} 2$ to downregulate DC-derived IL-12 production suggests that autocrine or paracrine interactions between DCs are capable of regulating IL-12 production. Thus, PD-L2-mediated regulation of immune responses is complex, being regulated via interactions between PD-L2 and at least two distinct receptors, both of which are expressed on DCs and T cells, and which have distinct effects based on the types of cells studied. Such complexities suggest that PD-L2 (and other family members) acts as a rheostat, modulating the responsiveness to immune mediators such as IL-13, rather than providing an "on/ off" switch for one particular type of response. However, our observation of differential expression levels of PD-L2 in human tissues taken from individuals with mild vs. severe asthma suggest that these subtle influences can have a substantial impact on disease severity.

Collectively, these data demonstrate that PD-L2 expression modulates the overall magnitude of AHR in allergic asthma. However, rather than directly regulating T-cell activity through interactions with its previously described receptor, PD-1, the dominant function of PD-L2 in vivo is inhibition of antigenpresenting cell-derived IL-12 through interactions with an unknown receptor. Moreover, PD-L2 stimulation of purified DCs directly inhibits IL-12 production, demonstrating that the 
unknown receptor is also expressed by DCs and suggesting that DC:DC interactions, either autocrine or paracrine, modulate IL-12 synthesis in vivo. Finally, these data also demonstrate that IL-12 can directly antagonize IL-13-driven gene transcription, highlighting a previously unappreciated role for IL-12 in modulating the activity of Th2 effector cytokines. Thus, in asthmatics, increased PD-L2 expression in the inflamed lung downregulates IL-12 secretion, facilitating greater IL-13 responsiveness and allowing the development of more severe AHR.

\section{METHODS}

Mice. Male A/J mice were purchased from Jackson Laboratories (Bar Harbor, ME) at 4 weeks of age and housed in a specific pathogen-free facility at Cincinnati Children's Hospital Medical Center. Experiments were initiated at 6 weeks of age. Animal experiments were approved by the CCHMC Institutional Animal Care and Use Committee.

Treatment protocols. Mice were treated with $40 \mu \mathrm{l}$ PBS, HDM (100 $\mu \mathrm{g}$; Greer Laboratories, Lenoir, NC), or AlexaFluor405-labeled (Invitrogen, Carlsbad, CA) HDM (AF405-HDM) IT on days 0 and 14. Where indicated, mice were treated with low-endotoxin OVA (Worthington Biochemicals, Lakewood, NJ) to induce AHR (10 $\mu \mathrm{g}$ IP on day 0 and $100 \mu \mathrm{g}$ IT on days 14 and 21$)$ or tolerance $(100 \mu \mathrm{g}$ IT on days 0,14 , and 21). Mice were treated IP with $250 \mu \mathrm{g}$ anti-PD-L2 $\left(\right.$ TY2 $\left.5^{18,26}\right)$, anti-PD-1 (RMP1-14 ${ }^{36}$ ), or control rat IgG I $_{2 \mathrm{a}}$ (GL117) $6 \mathrm{~h}$ before and $48 \mathrm{~h}$ following each allergen exposure. Where indicated, mice were also treated with $1 \mathrm{mg}$ of anti-IL-12 (clone C17.8, a gift of Dr. Fred Finkelman, University of Cincinnati) or control rat $\operatorname{IgG}_{2 \mathrm{a}}$ (GL117) on days -2 and 12.

Assessment of allergen-induced AHR. AHR was measured by assessing changes in tracheal pressure following administration of a cholinergic agonist over time and expressed as the airway pressure time index and is described in detail elsewhere. ${ }^{31}$ Importantly, this parameter has been shown to provide data similar to Flexivent-derived data generated using a full-dose response of inhaled methacholine. ${ }^{61}$ To evaluate AHR, mice were anaesthetized, intubated, and respirated at a rate of 120 breaths per minute with a constant tidal volume $(0.2 \mathrm{ml})$ and paralyzed with decamethonium bromide $\left(25 \mathrm{mg} \mathrm{kg}^{-1}\right) 72 \mathrm{~h}$ after final allergen challenge. Acetylcholine $\left(50 \mu \mathrm{g} \mathrm{kg}^{-1}\right)$ was injected into the inferior vena cava and dynamic airway pressure $\left(\mathrm{cm} \mathrm{H}_{2} \mathrm{O} \times \mathrm{sec}\right)$ followed for $5 \mathrm{~min}$. Blood was collected to measure total $\operatorname{IgE}$ and HDM-specific IgG $\mathrm{Ig}_{1}$ and $\mathrm{IgG}_{2 \mathrm{a}}$. To collect BALF, lungs were lavaged with Hank's Balanced Salt Solution (Invitrogen). Cells were recovered by centrifugation and total cells counted. Slides were prepared by cytocentrifugation and stained with Diff-Quik (Dade Behring, Düdingen, Switzerland) for differential cell counts.

Lung cell isolation. After AHR measurements, lungs were removed, minced, and placed in $6 \mathrm{ml}$ of RPMI 1640 containing Liberase CI $\left(0.5 \mathrm{mg} \mathrm{ml}^{-1}\right.$; Roche Diagnostics, Indianapolis, IN) and DNase I $\left(0.5 \mathrm{mg} \mathrm{ml}^{-1}\right.$; Sigma, St Louis, MO) at $37^{\circ} \mathrm{C}$ for $45 \mathrm{~min}$. The remaining tissue was forced through a 70 -micron cell strainer, and red blood cells were lysed with ACK (ammonium chloride-potassium) lysis buffer (Invitrogen). Cells were washed with RPMI containing 10\% fetal bovine serum FBS, viable cells were counted via trypan blue exclusion. Where indicated, lung cells were cultured at 350,000 cells per well of a 96-well plate $(250 \mu \mathrm{l}$ final volume) with HDM $\left(30 \mu \mathrm{g} \mathrm{ml}^{-1}\right)$. Tissue culture supernatants were harvested at $72 \mathrm{~h}$.

Flow cytometry. Staining reactions were performed at $4{ }^{\circ} \mathrm{C}$ following incubation with FcBlock (mAb 2.4G2) for 30 min. Alveolar macrophages $\left(\mathrm{CD} 11 \mathrm{c}^{\text {bright }}, \mathrm{CD} 11 \mathrm{~b}^{\text {neg }}, \mathrm{CD} 317^{\text {neg }}\right)$, plasmacytoid DCs $\left(\mathrm{CD} 11 \mathrm{c}^{\text {dim }} \mathrm{CD} 11 \mathrm{~b}^{\text {neg }} \mathrm{CD} 317^{+}\right)$, neutrophils (CD $11 \mathrm{c}^{\text {bright }} \mathrm{CD} 11 \mathrm{~b}-$ brightGrlbright $C D 103^{\text {neg }}$ ), inflammatory DCs (CD11 $c^{\text {bright }} C D 11$ bbrightGrldim $\left.\mathrm{CD} 103^{\text {neg }}\right)$, and $\mathrm{mDCs}\left(\mathrm{CD} 11 \mathrm{c}^{\text {bright }} \mathrm{CD} 11 \mathrm{~b}^{\text {bright }} \mathrm{Gr} 1^{\text {neg }}\right.$
CD103 ${ }^{\text {neg }}$ ) were quantified using anti-CD11c-PerCPCy5.5 (HL3), anti-CD11b-PE-Cy7 (M1/70), anti-Gr1-APC-Cy7 (RB6-8C5), anti-CD103-FITC (2E7), and anti-CD317-AF647 (eBio129c). Co-stimulatory molecule expression was examined using phycoerythrin-conjugated $\mathrm{mAbs}$ to major histocompatibility complex class II (14-4-4s) and PD-L2 (TY25). mAbs were purchased from eBioscience (San Diego, CA). Antigen uptake was measured in the Pacific Blue channel following administration of AF405-conjugated HDM. Dead cells were excluded using Live/Dead Blue (Invitrogen). Data were acquired with an LSRII flow cytometer equipped with lasers tuned to $355 \mathrm{~nm}, 405 \mathrm{~nm}, 488 \mathrm{~nm}, 562 \mathrm{~nm}$, and $640 \mathrm{~nm}$, and digital DiVa Software (BD Biosciences, San Jose, CA). FlowJo software (Treestar, Ashland, OR) was used to compensate spectral overlap and analyze data.

Subject recruitment. Subjects with no asthma or well-defined mild and severe asthma were recruited from the Montreal Chest Institute and Sacré-Coeur Hospital (Montreal, Quebec, Canada) based on the criteria of the American Thoracic Society workshop for Refractory Asthma. ${ }^{62}$ As described elsewhere, ${ }^{63}$ mild asthmatics had FEV (forced expiratory volume in one second) readings $\geq 70 \%$ postbronchodilator and required infrequent use of inhaled short-acting $\beta_{2}$-agonist medication alone. Severe asthmatics had at least one of (1) treatment with daily oral steroids for $>50 \%$ of the previous 12 months or (2) treatment with high-dose inhaled steroids and at least one other addon therapy continuously over the past 12 months. In addition, two or more of the following were required: (1) daily use of short-acting $\beta$-agonist; (2) persistent airflow obstruction as documented by prebronchodilator $\mathrm{FEV}_{1}<70 \%$ and $\mathrm{FEV}_{1} / \mathrm{FVC}$ (forced vital capacity) ratio $<80 \%$ predicted; ( 3 ) at least one urgent care visit in the previous 12 months; (4) $\geq 3$ steroid bursts in the previous 12 months; (5) prompt deterioration with $<25 \%$ dose reduction of steroids; or (6) a near-fatal asthma event in the past 3 years. Detailed definition of the inclusion and exclusion criteria for the enrollment of asthmatic subjects were reported previously. ${ }^{63}$ The protocols for the study were reviewed and approved by the ethics committees of both hospitals, and informed consent was obtained from all participating subjects. RNA was extracted from lung biopsies using the RNeasy columns, reverse transcribed with oligo(dT) (Amersham) and Superscript II (Invitrogen), in the presence of RNAguard (Amersham, Piscataway, NJ).

Quantitative RT-PCR. PCR primer pairs for mPD-L2, mFIZZ1, mArg1, mSPRR2b, mCD206, mC3, mS14, mIL-5, mIL-13, mAMCase, mIL-33, mIFN- $\gamma$, mPD-L1, hPD-L2, and hS9 were obtained from the mouse or human primer depot ${ }^{64}$ and designed to span an intronic region to avoid co-amplification of genomic DNA. Gene expression in mouse cells was analyzed by RT-PCR using the iCycler system (Bio-Rad, Hercules, CA) and SYBR green, while gene expression in human bronchial biopsies was done by RT-PCR using the StepOnePlus PCR system (Applied Biosystems, San Francisco, CA) and SYBR green. Gene expression analysis was performed using the $\Delta \Delta \mathrm{Ct}$ method described elsewhere. ${ }^{65}$

Generation and stimulation of BMDCs. Bone marrow cells $\left(3 \times 10^{5}\right.$ cells $\mathrm{ml}^{-1}$ ) were cultured in complete RPMI 1640 supplemented with granulocyte macrophages colony-stimulating factor $\left(10 \mathrm{ng} \mathrm{m}^{-1}\right.$, Peprotech, Rocky Hill, NJ). Medium was changed on day 3 and harvested on day 6 . In all, 250,000 cells were plated on wells coated with $5 \mu \mathrm{g} \mathrm{ml}^{-1}$ PD-L1-Fc, PD-L2-Fc, or control IgG-Fc (R\&D Systems) and stimulated with $30 \mu \mathrm{g} \mathrm{ml}^{-1} \mathrm{HDM}$ or $100 \mathrm{ng} \mathrm{ml}^{-1} \mathrm{LPS}$ for $24 \mathrm{~h}$. Culture supernatants were harvested to assay IL-12 p70, IL-6, TNF- $\alpha$, IL-1 $\beta$ (Pharmingen, San Diego, CA), and IL-23 (R\&D Systems, Minneapolis, MN) by enzyme-linked immunosorbent assay. Where indicated, BMDCs were stimulated with IL-12, IL-13, or IL-12 + IL-13 (all $10 \mathrm{ng} \mathrm{ml}^{-1}$ ) for $24 \mathrm{~h}$. RNA was harvested for PCR analysis. Where indicated, cultures also included anti-PD-1 (clone RMP1-14; eBioscience) at $5 \mu \mathrm{g} \mathrm{ml}^{-1}$. 
Mouse tracheal epithelial cells isolation. Tracheas from 4-6-weekold mice were removed from the thyroid cartilage to the level of bifurcation and incubated in Pronase $\left(1 \mathrm{mg} \mathrm{ml}^{-9}\right.$; Roche Applied Science, Indianapolis, IN) and incubated $\left(18 \mathrm{~h} \times 4{ }^{\circ} \mathrm{C}\right.$ while rocking). The next day, $10 \%$ FBS and $1 \mathrm{mg} \mathrm{ml}^{-1}$ DNase (Sigma-Aldrich, St Louis, MO) were added, and the tube inverted multiple times. The trachea was discarded; cells were washed and plated onto a cell culture plate with Primaria surface treatment (BD Biosciences, Bedford, MA) for $4 \mathrm{~h}$ to remove fibroblasts. Non-attached cells were washed, counted, and plated in DMEM/F12 (50/50) containing L-glutamine $(2 \mathrm{~mm})$, penicillin $\left(100 \mathrm{U} \mathrm{ml}^{-1}\right) /$ streptomycin $\left(100 \mu \mathrm{g} \mathrm{ml}^{-1}\right) \quad \mathrm{NaHCO}_{3} \quad(3.6 \mathrm{~mm})$, FBS (5\%), Cholera toxin $\left(0.1 \mu \mathrm{g} \mathrm{ml}^{-1}\right)$, mouse epithelial growth factor $\left(0.5 \mathrm{ng} \mathrm{ml}^{-1}\right)$, amphotericin $\mathrm{B}\left(0.25 \mu \mathrm{g} \mathrm{ml}^{-1}\right)$, bovine pituitary extract $\left(50 \mu \mathrm{g} \mathrm{ml}^{-1}\right)$, insulin-transferrin-selenium media supplement (Sigma Chemical, St Louis MO), and retinoic acid $\left(0.1 \mathrm{ng} \mathrm{ml}^{-1}\right)$. mTECs were grown on collagen-coated 6-well tissue culture plates until confluent. mTECs were stimulated with nothing, IL-13 $\left(10 \mathrm{ng} \mathrm{ml}^{-1}\right)$, or IL-12 + IL-13 (both at $10 \mathrm{ng} \mathrm{ml}^{-1}$ ) for $24 \mathrm{~h}$. Cells were lysed with Trizol, total RNA was isolated, and cDNA synthesized to measure gene expression by RT-PCR.

Western blot. For western blot analysis of STAT6 phosphorylation, $\mathrm{BMDCs}$ from $\mathrm{BABL} / \mathrm{c}$ mice were generated as described above. After harvest, 2.5 million BMDCs were plated in complete RPMI culture medium (containing $10 \%$ fetal bovine serum (FBS)) in single wells of a 24 -well plate and allowed to adhere for $12 \mathrm{~h}$. After $12 \mathrm{~h}$, the culture medium was removed, and BMDCs were starved in RPMI containing $0.1 \%$ FBS overnight. The following morning cells were stimulated with medium alone (containing $0.1 \%$ FBS), IL-12, IL-13, or IL-12 + IL-13 (all at $10 \mathrm{ng} \mathrm{ml}^{-1}$ ) for $15 \mathrm{~min}$. Cells were immediately placed on ice, washed with ice-cold PBS, and lysed with a lysis buffer containing protease inhibitors (Roche, Indianapolis, IN) and phosphatase inhibitor cocktails (CalBiochem, Gibbstown, NJ). Lysates were stored at $-80^{\circ} \mathrm{C}$ until required. Total proteins $(10 \mu \mathrm{g})$ were separated by electrophoresis on an sodium dodecyl sulfate polyacrylamide gel and transferred onto PVDF membranes and blocked with 5\% BSA for $1 \mathrm{~h}$ at room temperature. Afterwards, the membranes were incubated overnight with primary antibodies (in 5\% BSA in TBS) as follows: rabbit anti-human/mouse phospho-STAT6 (Tyr761) (1:10,000, Cell Signaling Technology, Beverly, MA), rabbit anti-mouse STAT6 (1:10,000, Cell Signaling Technology), or anti- $\alpha$-tubulin $(1: 10,000$, Cell Signaling Technology). Membranes were then washed and incubated for $1 \mathrm{~h}$ at room temperature with an HRP-conjugated goat anti-rabbit secondary (in 5\% BSA in TBS at 1:10,000, Cell Signaling Technology); blots were developed using an ECL Prime (GE Healthcare, Pittsburgh, PA).

Statistical analysis. To determine differences between multiple groups, analysis of variance was used with post hoc comparisons using Tukey's method. For comparison between two groups, a Student's $t$-test was performed. In human samples, analysis of variance was used with post hoc comparisons using the Kruskal-Wallis test. Significance was assumed at $P<0.05$.

SUPPLEMENTARY MATERIAL is linked to the online version of the paper at http://www.nature.com/mi

\section{ACKNOWLEDGEMENTS}

Funded by a Parker B. Francis Fellowship, an ATS Unrestricted Research Grant, and a CCHMC Trustee Grant to I.P.L. and NHLBI R01 HL67736-09, NIAID U19 A1070235, and NIAID R01 A1083315 to M.W.K.

\section{DISCLOSURE}

The authors declare no conflict of interest.

c) 2013 Society for Mucosal Immunology

\section{REFERENCES}

1. Wills-Karp, M. Interleukin-13 in asthma pathogenesis. Immunol. Rev. 202, 175-190 (2004).

2. Akdis, M. et al. Immune responses in healthy and allergic individuals are characterized by a fine balance between allergen-specific T regulatory 1 and T helper 2 cells. J. Exp. Med. 199, 1567-1575 (2004).

3. Ling, E.M. et al. Relation of CD4 + CD25 + regulatory T-cell suppression of allergen-driven T-cell activation to atopic status and expression of allergic disease. Lancet 363, 608-615 (2004).

4. Lewkowich, I.P., Lajoie, S., Clark, J.R., Herman, N.S., Sproles, A.A. Wills-Karp, M. Allergen uptake, activation, and IL-23 production by pulmonary myeloid DCs drives airway hyperresponsiveness in asthma-susceptible mice. PLoS One 3, e38792008).

5. Holt, P.G., Schon-Hegrad, M.A. \& Oliver, J. MHC class II antigen-bearing dendritic cells in pulmonary tissues of the rat. Regulation of antigen presentation activity by endogenous macrophage populations. J. Exp. Med. 167, 262-274 (1988).

6. Lambrecht, B.N., Salomon, B., Klatzmann, D. \& Pauwels, R.A. Dendritic cells are required for the development of chronic eosinophilic airway inflammation in response to inhaled antigen in sensitized mice. J. Immunol. 160, 4090-4097 (1998).

7. Lambrecht, B.N., Peleman, R.A., Bullock, G.R. \& Pauwels, R.A. Sensitization to inhaled antigen by intratracheal instillation of dendritic cells. Clin. Exp. Allergy 30, 214-224 (2000).

8. de Heer, H.J. et al. Essential role of lung plasmacytoid dendritic cells in preventing asthmatic reactions to harmless inhaled antigen. J. Exp. Med. 200, 89-98 (2004).

9. Kool, M. et al. An anti-inflammatory role for plasmacytoid dendritic cells in allergic airway inflammation. J. Immunol. 183, 1074-1082 (2009).

10. Lajoie, S. et al. Complement-mediated regulation of the IL-17A axis is a central genetic determinant of the severity of experimental allergic asthma. Nat. Immunol. 11, 928-935 (2010).

11. Keane-Myers, A., Wysocka, M., Trinchieri, G. \& Wills-Karp, M. Resistance to antigen-induced airway hyperresponsiveness requires endogenous production of IL-12. J. Immunol. 161, 919-926 (1998).

12. Gavett, S.H., O'Hearn, D.J., Li, X., Huang, S.K., Finkelman, F.D. Wills-Karp, M. Interleukin 12 inhibits antigen-induced airway hyperresponsiveness, inflammation, and Th2 cytokine expression in mice. J. Exp. Med. 182, 1527-1536 (1995).

13. Deurloo, D.T. et al. CD28/CTLA4 double deficient mice demonstrate crucial role for $\mathrm{B} 7 \mathrm{co}$-stimulation in the induction of allergic lower airways disease. Clin. Exp. Allergy 33, 1297-1304 (2003).

14. Hoshino, A. et al. Critical role for OX40 ligand in the development of pathogenic Th2 cells in a murine model of asthma. Eur. J. Immunol. 33, 861-869 (2003).

15. Keane-Myers, A.M., Gause, W.C., Finkelman, F.D., Xhou, X.D. Wills-Karp, M. Development of murine allergic asthma is dependent upon B7-2 costimulation. J. Immunol. 160, 1036-1043 (1998).

16. Akbari, O. et al. Antigen-specific regulatory $T$ cells develop via the ICOS-ICOS-ligand pathway and inhibit allergen-induced airway hyperreactivity. Nat. Med. 8, 1024-1032 (2002).

17. Keir, M.E. et al. Tissue expression of PD-L1 mediates peripheral T cell tolerance. J. Exp. Med. 203, 883-895 (2006).

18. Yamazaki, T. et al. Expression of programmed death 1 ligands by murine $T$ cells and APC. J. Immunol. 169, 5538-5545 (2002).

19. Ishida, Y., Agata, Y., Shibahara, K. \& Honjo, T. Induced expression of PD-1, a novel member of the immunoglobulin gene superfamily, upon programmed cell death. EMBO J. 11, 3887-3895 (1992).

20. Cho, H.Y. et al. Programmed death-1 receptor negatively regulates LPS-mediated IL-12 production and differentiation of murine macrophage RAW264.7 cells. Immunol. Lett. 127, 39-47 (2009).

21. Yao, S. et al. PD-1 on dendritic cells impedes innate immunity against bacterial infection. Blood 113, 5811-5818 (2009).

22. Barber, D.L. et al. Restoring function in exhausted CD8 T cells during chronic viral infection. Nature 439, 682-687 (2006).

23. Trautmann, L. et al. Upregulation of PD-1 expression on HIV-specific CD8 $+\mathrm{T}$ cells leads to reversible immune dysfunction. Nat. Med. 12, 1198-1202 (2006).

24. Ozkaynak, E. et al. Programmed death-1 targeting can promote allograft survival. J. Immunol. 169, 6546-6553 (2002). 
25. Nishimura, H., Nose, M., Hiai, H., Minato, N. \& Honjo, T. Development of lupus-like autoimmune diseases by disruption of the PD-1 gene encoding an ITIM motif-carrying immunoreceptor. Immunity 11, 141-151 (1999).

26. Matsumoto, $\mathrm{K}$. et al. B7-DC regulates asthmatic response by an IFN-gamma-dependent mechanism. J. Immunol. 172, 2530-2541 (2004).

27. Akbari, O. et al. PD-L1 and PD-L2 modulate airway inflammation and iNKT-cell-dependent airway hyperreactivity in opposing directions. Mucosal Immunol. 3, 81-91 (2010).

28. Matsumoto, K. et al. B7-DC induced by IL-13 works as a feedback regulator in the effector phase of allergic asthma. Biochem. Biophys. Res. Commun. 365, 170-175 (2008).

29. McGee, H.S., Yagita, H., Shao, Z. \& Agrawal, D.K. PD-1 Antibody Blocks Therapeutic Effects of T-regulatory Cells in Cockroach Antigen-induced Allergic Asthma. Am. J. Respir. Cell Mol. Biol. 43, 432-442 (2010).

30. Oflazoglu, E. et al. Paradoxical role of programmed death-1 ligand 2 in Th2 immune responses in vitro and in a mouse asthma model in vivo. Eur. J. Immunol. 34, 3326-3336 (2004).

31. Levitt, R.C. \& Mitzner, W. Expression of airway hyperreactivity to acetylcholine as a simple autosomal recessive trait in mice. FASEB J. 2, 2605-2608 (1988).

32. Tsushima, F. et al. Preferential contribution of $\mathrm{B} 7-\mathrm{H} 1$ to programmed death-1-mediated regulation of hapten-specific allergic inflammatory responses. Eur. J. Immunol. 33, 2773-2782 (2003).

33. Tseng, S.Y. et al. B7-DC, a new dendritic cell molecule with potent costimulatory properties for T cells. J. Exp. Med. 193, 839-846 (2001).

34. Shin, T. et al. Cooperative B7-1/2 (CD80/CD86) and B7-DC costimulation of CD4 + Tcells independent of the PD-1 receptor. J Exp Med 198, 31-38 (2003).

35. Wang, S., Bajorath, J., Flies, D.B., Dong, H., Honjo, T. \& Chen, L. Molecular modeling and functional mapping of $\mathrm{B} 7-\mathrm{H} 1$ and $\mathrm{B} 7-\mathrm{DC}$ uncouple costimulatory function from PD-1 interaction. J. Exp. Med. 197 1083-1091 (2003).

36. Yamazaki, T., Akiba, H., Koyanagi, A., Azuma, M., Yagita, H. \& Okumura, K. Blockade of $\mathrm{B} 7-\mathrm{H} 1$ on macrophages suppresses $\mathrm{CD} 4+$ Tcell proliferation by augmenting IFN-gamma-induced nitric oxide production. J. Immunol. 175, 1586-1592 (2005).

37. Lewkowich, I.P., Rempel, J.D. \& HayGlass, K.T. In vivo IgE levels in exogenous antigen stimulated responses: measurement of total lgE as a valid, simple surrogate for Ag-specific IgE. J. Immunol. Methods 286, 123-132 (2004).

38. Wills-Karp, M. et al. Interleukin-13: central mediator of allergic asthma. Science 282, 2258-2261 (1998).

39. Kuperman, D.A. et al. Direct effects of interleukin-13 on epithelial cells cause airway hyperreactivity and mucus overproduction in asthma. Nat. Med. 8, 885-889 (2002).

40. Rempel, J.D., Wang, M.D. \& HayGlass, K.T. Failure of rlL-12 administration to inhibit established $\operatorname{lgE}$ responses in vivo is associated with enhanced IL-4 synthesis by non-B/non-T cells. Int. Immunol. 12 , 1025-1034 (2000).

41. Zhu, R. et al. The Pro-Th1 cytokine IL-12 enhances IL-4 production by invariant NKT cells: relevance for T cell-mediated hepatitis. J. Immunol. 178, 5435-5442 (2007).

42. Ford, A.Q., Dasgupta, P., Mikhailenko, I., Smith, E.M., Noben-Trauth, N. \& Keegan, A.D. Adoptive transfer of IL-4Ralpha + macrophages is sufficient to enhance eosinophilic inflammation in a mouse model of allergic lung inflammation. BMC Immunol. 13, 62012).

43. Melgert, B.N. et al. Macrophages: regulators of sex differences in asthma? Am. J. Respir. Cell Mol. Biol. 42, 595-603 (2010).

44. Deslee, G. et al. Involvement of the mannose receptor in the uptake of Der $p$ 1, a major mite allergen, by human dendritic cells. J. Allergy Clin. Immunol. 110, 763-770 (2002).
45. Kurowska-Stolarska, M. et al. IL-33 induces antigen-specific IL-5 + Tcells and promotes allergic-induced airway inflammation independent of IL-4. J. Immunol. 181, 4780-4790 (2008).

46. Wills-Karp, M. et al. Trefoil factor 2 rapidly induces interleukin 33 to promote type 2 immunity during allergic asthma and hookworm infection. J. Exp. Med. 209, 607-622 (2012).

47. Fitz, L.J. et al. Acidic mammalian chitinase is not a critical target for allergic airway disease. Am. J. Respir. Cell Mol. Biol. 46, 71-79 (2012).

48. Yang, C.J. et al. Inhibition of acidic mammalian chitinase by RNA interference suppresses ovalbumin-sensitized allergic asthma. Hum. Gene Ther. 20, 1597-1606 (2009).

49. Doherty, T.A. et al. Alternaria induces STAT6-dependent acute airway eosinophilia and epithelial FIZZ1 expression that promotes airway fibrosis and epithelial thickness. J. Immunol. 188, 2622-2629 (2012).

50. Finkelman, F.D. et al. Suppressive effect of IL-4 on IL-13-induced genes in mouse lung. J. Immunol. 174, 4630-4638 (2005).

51. Mathew, A., MacLean, J.A., DeHaan, E., Tager, A.M. \& Green, F.H. Luster AD. Signal transducer and activator of transcription 6 controls chemokine production and $\mathrm{T}$ helper cell type 2 cell trafficking in allergic pulmonary inflammation. J. Exp. Med. 193, 1087-1096 (2001).

52. Kuperman, D., Schofield, B., Wills-Karp, M. \& Grusby, M.J. Signal transducer and activator of transcription factor 6 (Stat6)-deficient mice are protected from antigen-induced airway hyperresponsiveness and mucus production. J. Exp. Med. 187, 939-948 (1998).

53. Onari, Y. et al. IL-12p40 is essential for the down-regulation of airway hyperresponsiveness in a mouse model of bronchial asthma with prolonged antigen exposure. Clin. Exp. Allergy 39, 290-298 (2009).

54. Raman, K., Kaplan, M.H., Hogaboam, C.M., Berlin, A. \& Lukacs, N.W. STAT4 signal pathways regulate inflammation and airway physiology changes in allergic airway inflammation locally via alteration of chemokines. J. Immunol. 170, 3859-3865 (2003).

55. Morahan, G. et al. Association of IL12B promoter polymorphism with severity of atopic and non-atopic asthma in children. Lancet 360, 455-459 (2002).

56. Freeman, G.J. et al. Engagement of the PD-1 immunoinhibitory receptor by a novel B7 family member leads to negative regulation of lymphocyte activation. J. Exp. Med. 192, 1027-1034 (2000).

57. Latchman, Y. et al. PD-L2 is a second ligand for PD-1 and inhibits T cell activation. Nat. Immunol. 2, 261-268 (2001).

58. Pfistershammer, K. et al. No evidence for dualism in function and receptors: PD-L2/B7-DC is an inhibitory regulator of human T cell activation. Eur. J. Immunol. 36, 1104-1113 (2006).

59. Said, E.A. et al. Programmed death-1-induced interleukin-10 production by monocytes impairs CD4(+) T cell activation during HIV infection. Nat. Med. 16, 452-459 (2010).

60. Shin, T. et al. In vivo costimulatory role of B7-DC in tuning T helper cell 1 and cytotoxic T lymphocyte responses. J. Exp. Med. 201, 1531-1541 (2005).

61. Perkins, C. et al. Selective stimulation of IL-4 receptor on smooth muscle induces airway hyperresponsiveness in mice. J. Exp. Med. 208, 853-867 (2011).

62. Wenzel, S.E., Fahy, J.V., Irvin, C., Petors, S.P., Spector, S. \& Szefler, S.J. Proceedings of the ATS workshop on refractory asthma: current understanding, recommendations, and unanswered questions. American Thoracic Society. Am. J. Respir. Crit. Care Med. 162, 2341-2351 (2000).

63. Foley, S.C. et al. Increased expression of ADAM33 and ADAM8 with disease progression in asthma. J. Allergy Clin. Immunol. 119, 863-871 (2007).

64. Cui, W., Taub, D.D. \& Gardner, K. qPrimerDepot: a primer database for quantitative real time PCR. Nucleic Acids Res. 35 (Database Issue), D805-D809 (2007).

65. Livak, K.J. \& Schmittgen, T.D. Analysis of relative gene expression data using real-time quantitative PCR and the 2(-Delta Delta C(T)) Method. Methods 25, 402-408 (2001). 